Supplement of The Cryosphere, 16, 667-688, 2022

https://doi.org/10.5194/tc-16-667-2022-supplement

(c) Author(s) 2022. CC BY 4.0 License.

(c) (1)

Tre crospheres GGU

Supplement of

\title{
Microstructure, micro-inclusions, and mineralogy along the EGRIP (East Greenland Ice Core Project) ice core - Part 2: Implications for palaeo-mineralogy
}

Nicolas Stoll et al.

Correspondence to: Nicolas Stoll (nicolas.stoll@awi.de)

The copyright of individual parts of the supplement might differ from the article licence. 

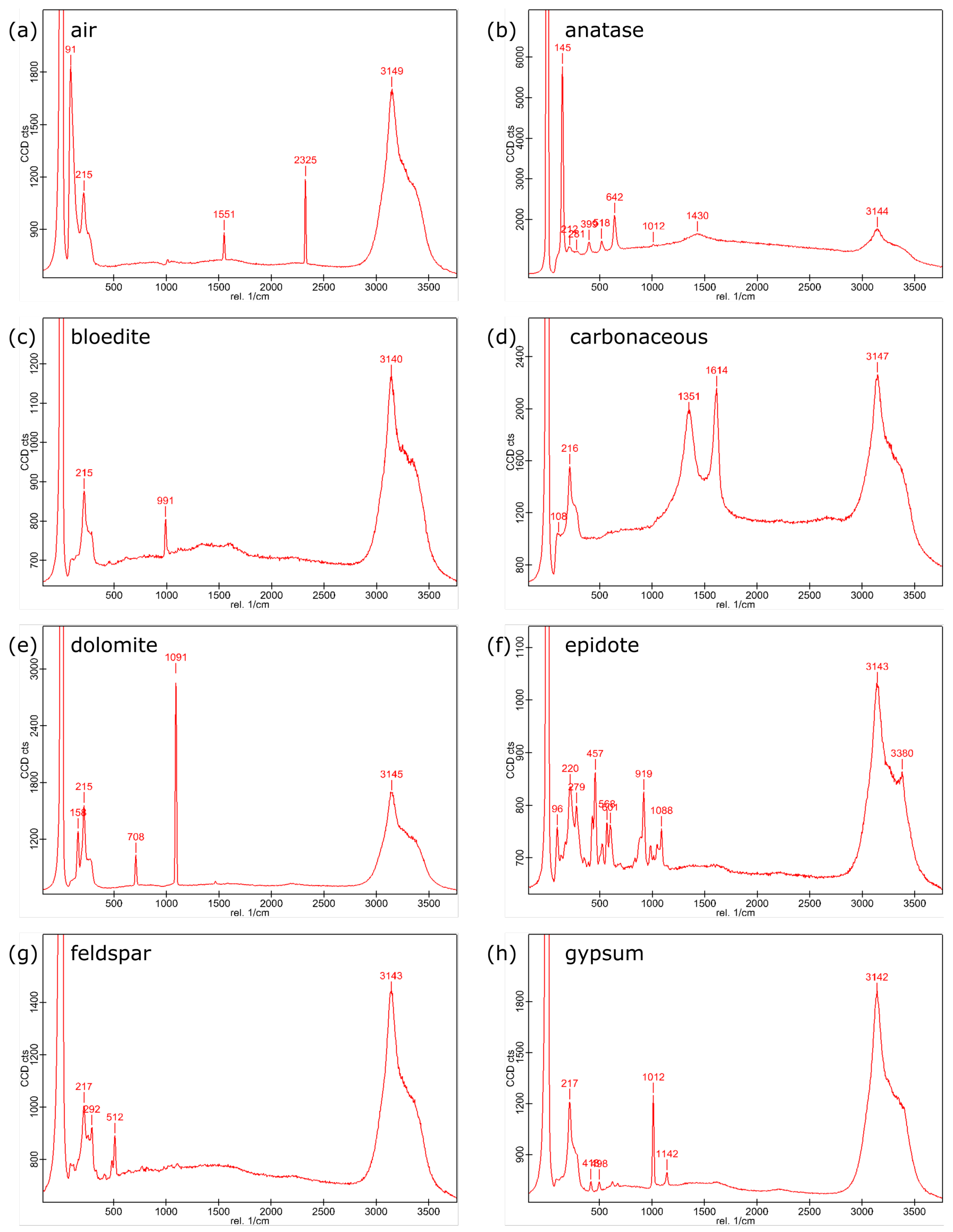
(i)

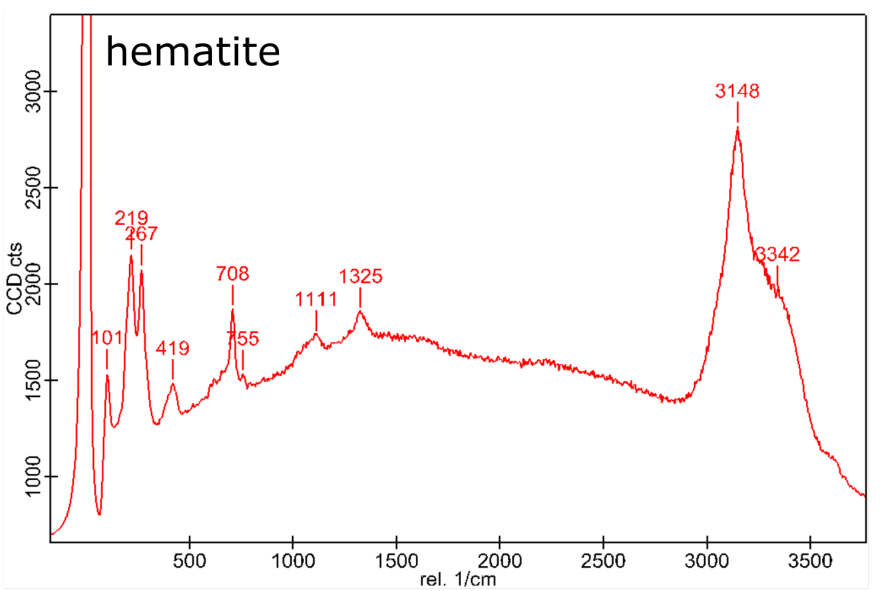

(k)

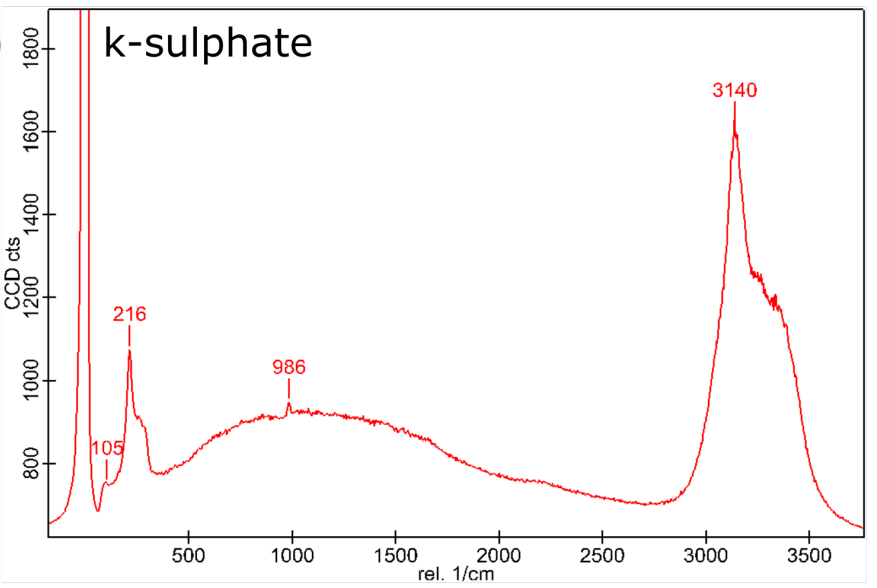

(m)

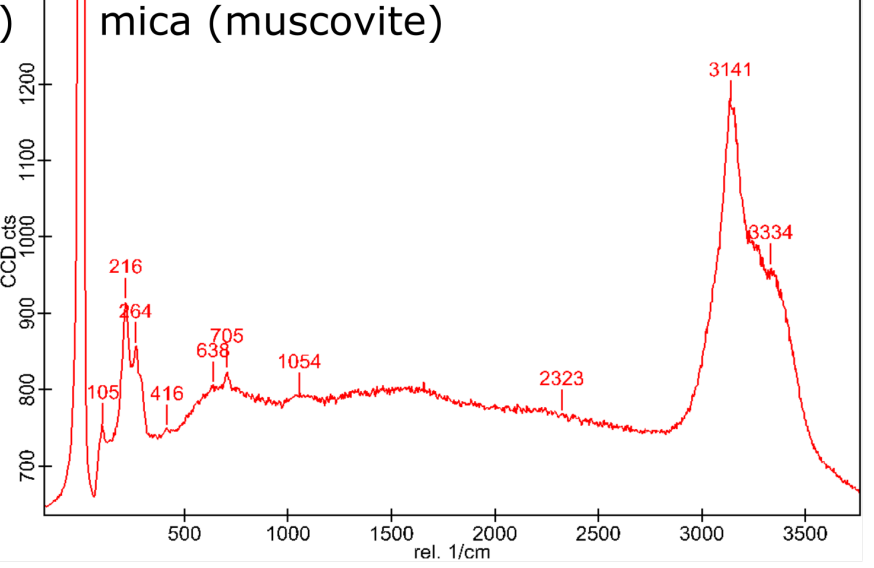

(o)

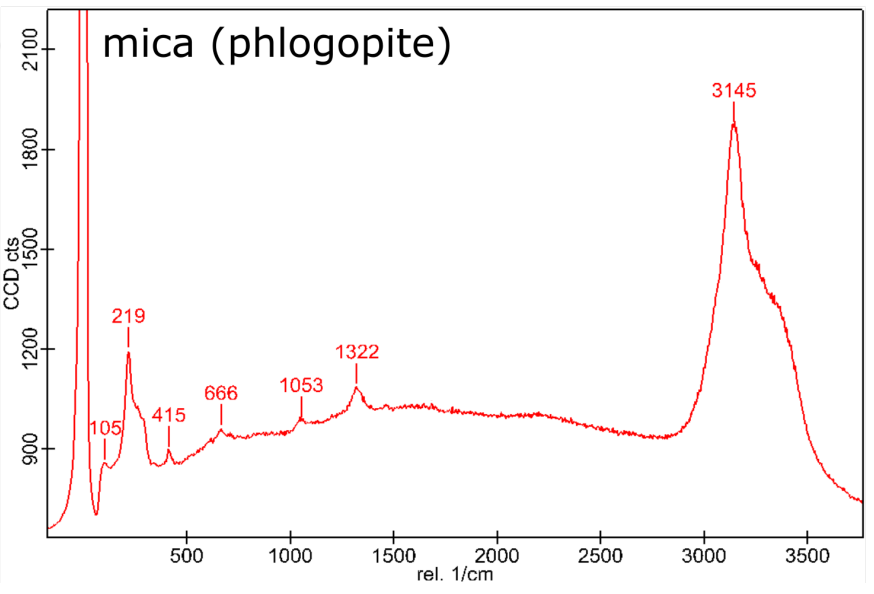

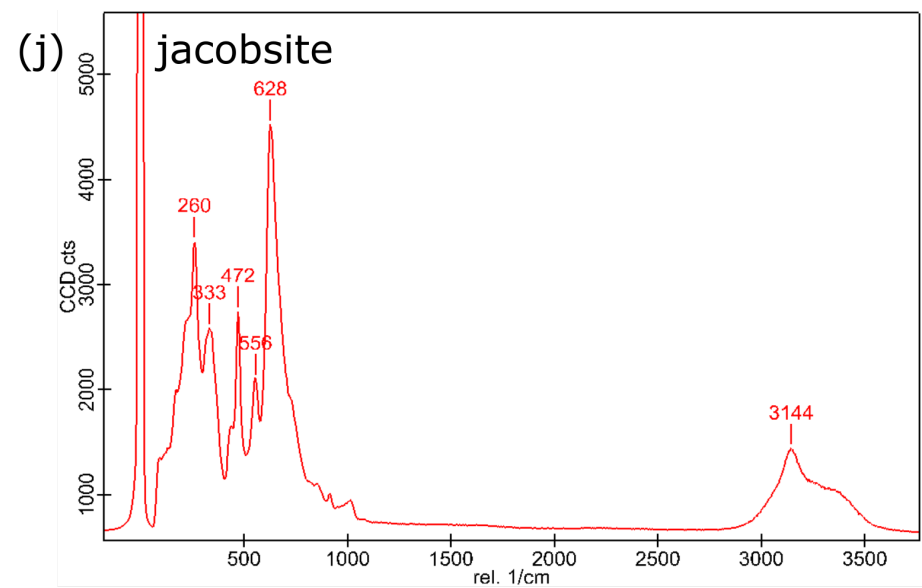

(I)

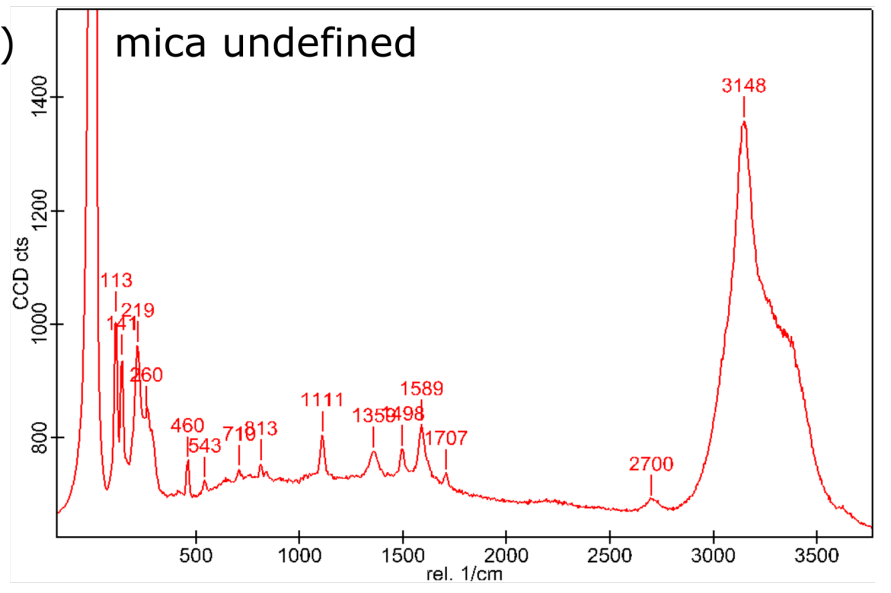

$(n)_{\substack{\circ \\ \hdashline}}$ mica (paragonite)

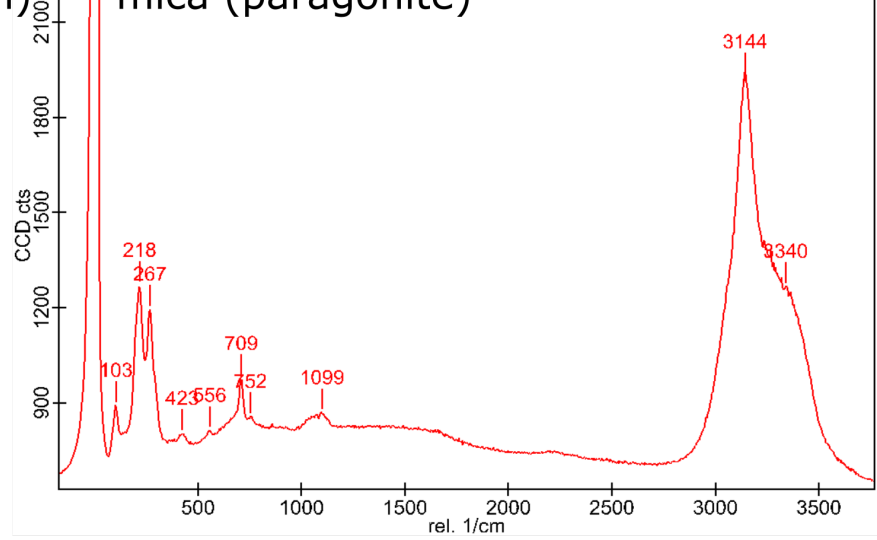

(p)

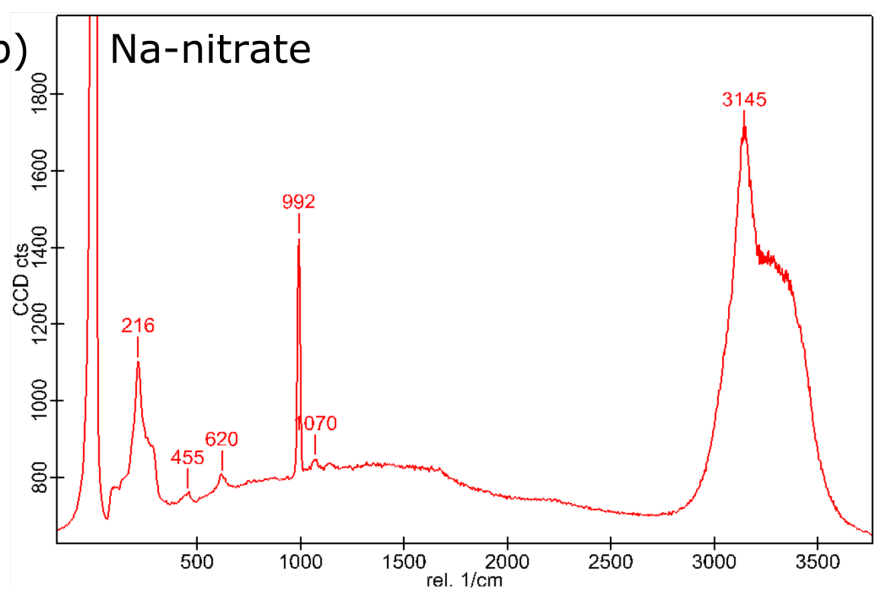


(q)

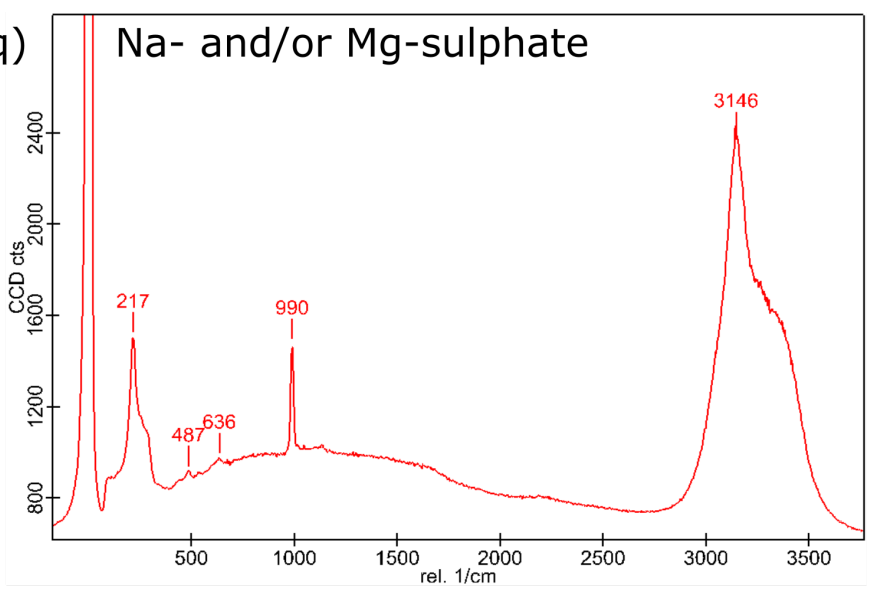

(s)

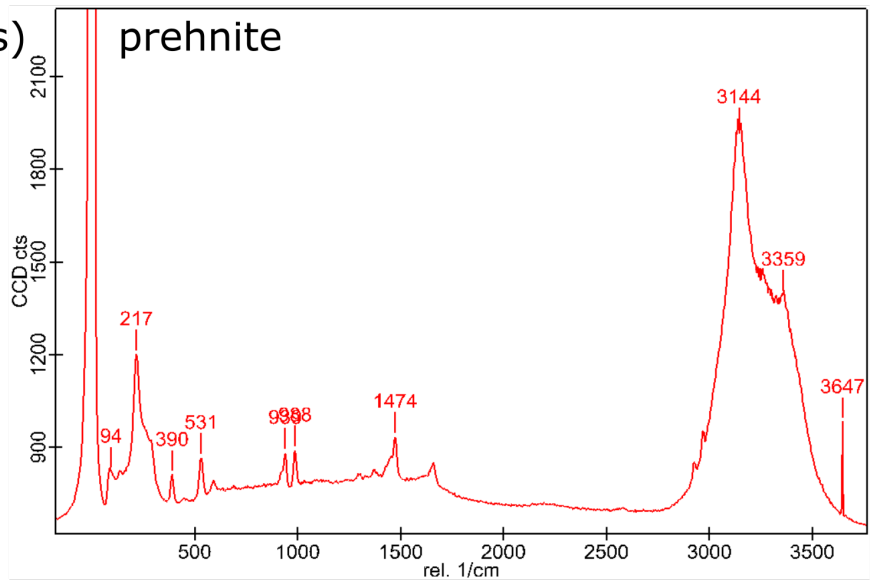

(u)
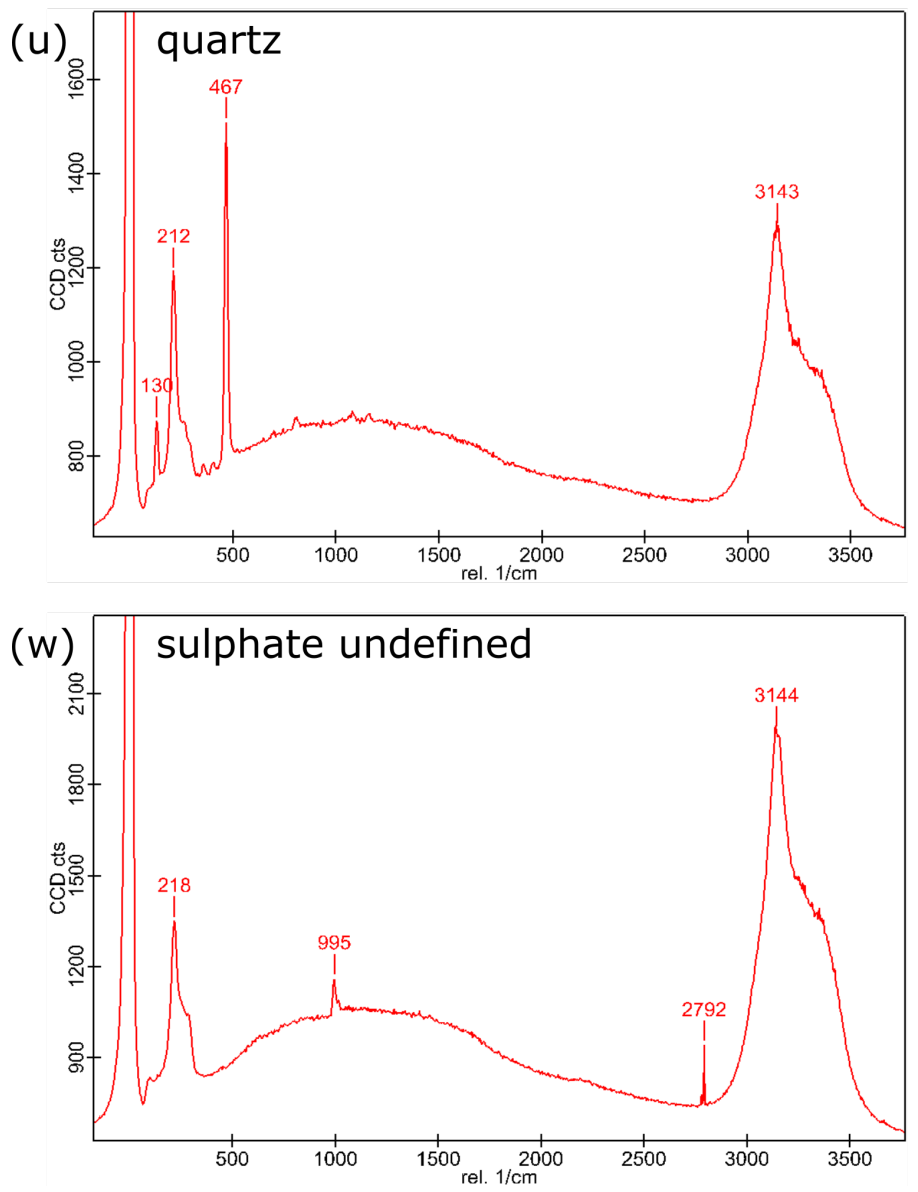

(r)

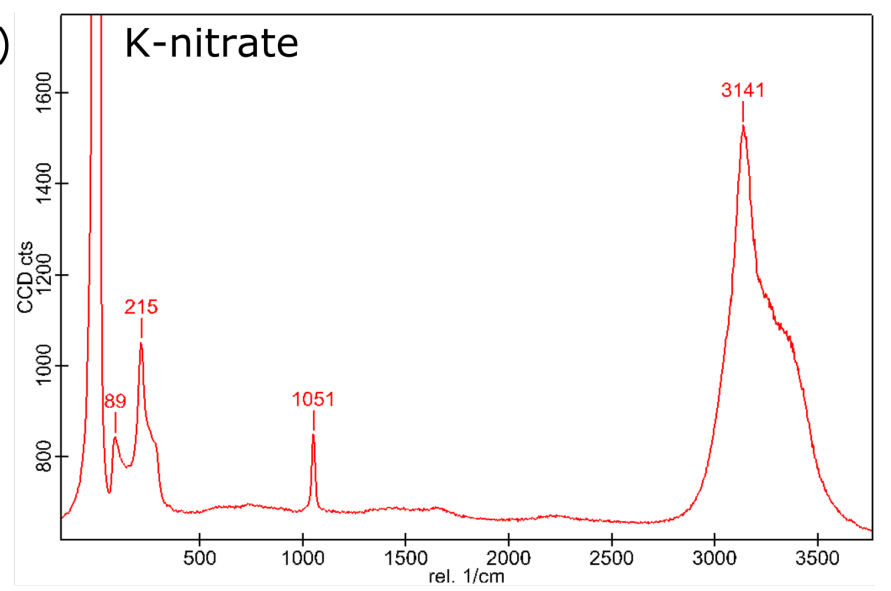

(t)

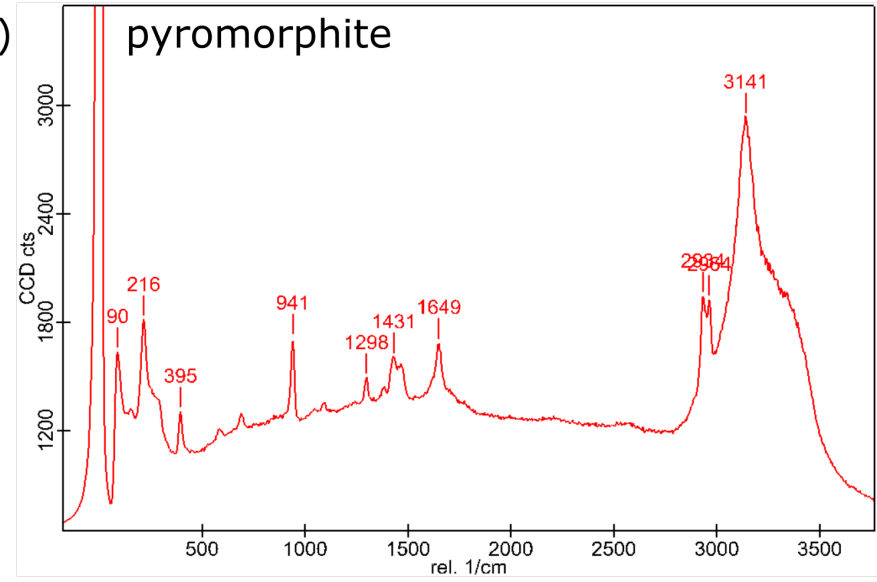

(v)

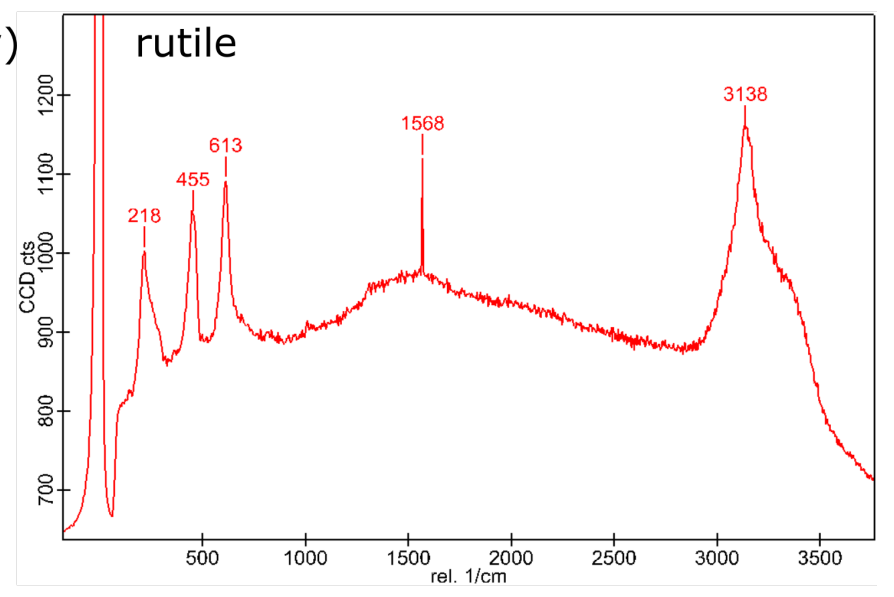

(x)

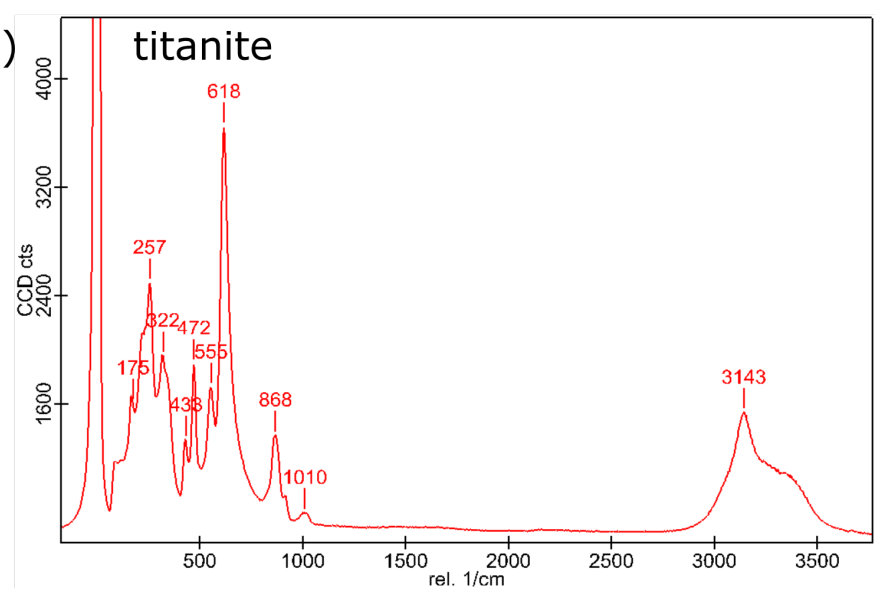

